\title{
Multi Unit Selective Inventory Control- A Three Dimensional Approach (MUSIC -3D)
}

\author{
V.R. Girija ${ }^{1}$ and Prof. M.S. Bhat ${ }^{2}$ \\ ${ }^{1}$ Asst. Professor, Deccan School of Management, Dept. of Hospital Management, Hyderabad, India \\ Email: girijat4@yahoo.com \\ 2 Head \& Professor, Department of E.I.E, CVR College of Engineering, Ibrahimpatnam, Hyderabad, India \\ Email: bhatms@rediffmail.com
}

\begin{abstract}
Materials contribute to a major cost factor in any enterprise. In health care institutions about 40 percent of the budgetary allocation is on procurement and management of stores. It includes all activities of stores from the stage of forecasting, utilization to final disposal. Stores management to be effective and efficient should aim to optimize the available resources.

Modern day health care institutions are multifaceted and multidimensional dynamic organizations. In the integrated and complex role of a hospital, the stores have a pivotal function. The stores management in a hospital covers from simple house-keeping materials to vital life-saving drugs.

In the present study MUSIC -3D (Multi Unit Selective Inventory Control- A Three Dimensional Approach) analysis of pharmacy drugs is performed at two multispecialty hospitals in Hyderabad. The study is based on the secondary data collected from the records of the pharmacy stores from both the hospitals, as well as informal interviews with pharmacists, doctors and nurses. MUSIC-3D analysis for pharmacy drugs is conducted on the basis of ABC, VED and SDE analysis.
\end{abstract}

Index terms-ABC analysis, Drugs, Inventory control, MUSIC - 3D analysis, pharmacy, SDE analysis, VED analysis.

\section{INTRODUCTION}

The goal of effective inventory management is to satisfy customers' expectations of product availability with the amount of each item that will optimize hospital net costs. Inventory management is a crucial process that any business must undertake with the paramount care. A common mistake made in this process occurs when a company assesses its entire inventory at the same level. In fact, items have different worth to a company, even though they may all be required on day to day basis and shortage of these crucial items could be damaging. ABC analysis helps in classifying these inventory items based on their worth to the hospital. A further improvement on the technique utilized in the study has been Multiunit Selective Inventory Control 98
A Three Dimensional Approach (MUSIC-3D) criteria of annual usage value, availability and criticality.

Hospital pharmacy should ensure adequate stock of all the required drugs to maintain uninterrupted supply. It is necessary to have an effective and efficient management of pharmacy store by keeping a close supervision on important drugs, prevention of pilferage, and priority setting in purchase and distribution of drugs. Of all inventory control systems available, MUSIC-3D is more advanced way of storing drugs.

\section{LITERATURE REVIEW}

'Ref. [1]' suggested that MUSIC-3D is a powerful approach in the direction of cost reduction and application of scientific management principles in hospital. .MUSIC-3D is useful to purchase executive, to take decisions on a scientific and practical basis.

'Ref. [2]' discusses integrated picture of MUSIC-3D. As per this model, the items in the stores may be grouped in three-dimensions on the basis of consumption value, availability and criticality. In this method, two levels for each of the three dimensionshigh consumption / low consumption value, long leadtime / short lead-time and critical / non-critical categories are advocated.

'Ref. [3]' feels that prioritizing items for management attention has been advocated in operations management for a long time, normally using $\mathrm{ABC}$ analysis (inventory control). This focuses attention on the "A" category items to maximize managerial effectiveness. Empirical evidence shows that this is a reasonable rule for allocating scarce resource and management time but presents difficulties when the manager has to take more than one important dimension of a situation into account. 'Ref. [3]' presents joint criteria matrix within the $\mathrm{ABC}$ framework and gives an industrial application. The joint criteria matrix has practical utility, provided, ranking on some scale of measurement is realistic. The appropriate number of 
categories must be defined by the user. Combining criteria will probably require different analytical approaches, e.g. goal programming or heuristic approaches. Utilization of the matrix by managers can provide an explicit method for taking a range of criteria into account in the development of inventory policies. 'Ref. [4]' develops an inventory strategy based on $\mathrm{ABC}$ analyst.

'Ref. [5]' analyzes that successful operation of a manufacturing firm depends to a large extent on an adequate inventory balance of raw materials and components. Excess inventory means a high amount of tied-up capital and a low inventory can produce interruption in the production flow. Appropriate inventory levels become even more crucial when part of the material is imported. Long lead times add to the uncertainty of demand between replenishments; in addition, import restriction by foreign countries where affiliates of multinational companies are located must also be taken into consideration. 'Ref. [5]' describes a USA-based company which is highly devalued by inflation because of mandatory bank deposits. An ABC analysis provided a good insight into the situation and enabled a considerable improvement in the company's performance.

'Ref. [6]' conducted ABC and VED (vital, essential, desirable) analysis of the pharmacy store of Post Graduate Institute of Medical Education and Research (PGIMER), Chandigarh, India to identify the categories of items needing stringent management control. The annual consumption and expenditure incurred on each item of pharmacy for the year 2007-08 was analyzed and inventory control techniques, i.e. ABC, VED and ABC-VED matrix analysis, were applied. The drug total annual drug expenditure (ADE) on items issued in 2007-08 was Rs. 40,012,612. ABC analysis revealed $13.78 \%, 21.85 \%$ and $64.37 \%$ items as A, B and C category items, respectively, accounting for $69.97 \%$, $19.95 \%$ and $10.08 \%$ of ADE of the pharmacy. VED analysis showed $12.11 \%, 59.38 \%$ and $28.51 \%$ items as $\mathrm{V}, \mathrm{E}$, and D category items, respectively, accounting for $17.14 \%, 72.38 \%$ and $10.48 \%$ of $\mathrm{ADE}$ of the pharmacy. On ABC-VED matrix analysis, $22.09 \%, 54.63 \%$ and $23.28 \%$ items were found to be category I, II and III items, respectively, accounting for $74.21 \%, 22.23 \%$ and $3.56 \%$ of ADE of the pharmacy.

'Ref. [7]' employed a matrix based on coupling of cost ABC (always, better and control) analysis and criticality (vital, essential and desirable) analysis for drug inventory containing 129 items of drug store in the Department of Community Medicine of a Medical financial difficulty for one of the Brazilian affiliates of formulary of the pharmacy consisted of 421 items. The

College in Delhi. The annual drug expenditure incurred on 129 drug items for the year 2010-2011 was found to be Rs. 4, 35,847.85. On ABC analysis, 18.6, 24.0 and $57.4 \%$ drugs were found to be A,B and C category items, respectively, amounting to $69.1,20.8$ and $10.1 \%$ of annual drug expenditure. About 13.2 (17), 38.8 (50) and $48.0 \%$ (62) items were found to be vital, essential and desirable category items, respectively, amounting to $18.7,49.5$ and $31.8 \%$ of annual drug expenditure. Based on ABC-vital, essential and desirable matrix analysis there were $37(28.68 \%)$ items in category I, 53 $(41.09 \%)$ items in category II and $39(30.23 \%)$ items in category III, amounting to $73.0,22.2$ and $4.8 \%$ of annual drug expenditure, respectively.

'Ref. [8]' formulates a matrix of nine groups based on cost and criticality, by combining $\mathrm{ABC}$ and VED analysis. 'Ref. [9]' observed that $\mathrm{ABC}$ analysis, if practiced, would allow effective control over two third of the total expenditure by controlling only one fourth of the items.

\section{OBJECTIVES OF THE STUDY}

1. To classify pharmacy drugs into ABC, VED $\&$ SDE categories.

2. To apply MUSIC-3D process of Inventory management to pharmacy drugs.

\section{METHODOLOGY}

In the present study, MUSIC -3D analysis of pharmacy drugs is performed at two multispecialty hospitals in Hyderabad. ABC Analysis is carried out by analysing the secondary data collected from the records of pharmacy department and stores (for surgical items). The records were observed for a period of 6 months i.e. from Jan 2013 to June 2013. To classify the items under VED, expert opinion of doctors \& nurses from the respective departments is considered .The opinions of pharmacists are also given due consideration. Informal Interview was conducted with the doctors, nurses and pharmacists to get their expert opinion regarding the criticality of the drugs. SDE analysis is done based on secondary data available in the records regarding the procurement of drugs, surgical items and their availability. Also an informal interview is conducted with the In-charges and other staff of stores \& pharmacy to collect the data regarding the availability of surgical items and drugs. MUSIC-3D analysis for pharmacy drugs and surgical items is conducted on the basis of ABC, VED and SDE analysis.

The classification of pharmacy drugs and surgical items under MUSIC-3D analysis is based on 3 
dimensions:

1. Consumption value (High or Low)

2. Criticality ( Critical or Non-Critical) and

3. Lead time (Long or Short)

The consumption values are in turn obtained through ABC analysis, Criticality though VED analysis and Lead time through SDE analysis.

\section{DATA ANALYSIS AND RESULTS}

As the classification of pharmacy drugs under MUSIC-3D analysis is based on 3 dimensions, to perform MUSIC-3 D, ABC VED \& SDE analysis are performed first.

$\mathrm{ABC}$ analysis of drugs of pharmacy department at Hospital 1 is shown in "Table 1". Here the drugs have been classified on the basis of consumption of items.

TABLE I

ABC ANALYSIS OF DRUGS OF PHARMACY DEPARTMENT AT HOSPITAL 1

\begin{tabular}{|c|c|c|c|}
\hline Category & Items & \% Items & $\begin{array}{c}\% \\
\text { Consumption(Value) }\end{array}$ \\
\hline 'A' items & 55 & 19.50 & 70.07791 \\
\hline 'B' items & 86 & 30.49 & 20.05315 \\
\hline 'C' items & 141 & 50 & 9.868941 \\
\hline $\begin{array}{c}\text { Total no } \\
\text { of items }\end{array}$ & 282 & 100 & 100 \\
\hline
\end{tabular}

As per "Table 1" the following are the interpretations of $\mathrm{ABC}$ analysis of pharmacy drugs at Hospital 1:

- 'A' Items: 55 items accounting for $19.5035 \%$ of total items \& $70.07791 \%$ of total consumption in terms of value.

- $\quad$ 'B' Items: 86 items accounting for $30.4964 \%$ of total items \& $20.05315 \%$ of total consumption.

- 'C' Items: 141 items accounting for $50 \%$ of total items \& $9.868 \%$ of total consumption.

$\mathrm{ABC}$ analysis of pharmacy drugs at Hospital 1 is also shown graphically in "Figure 1"

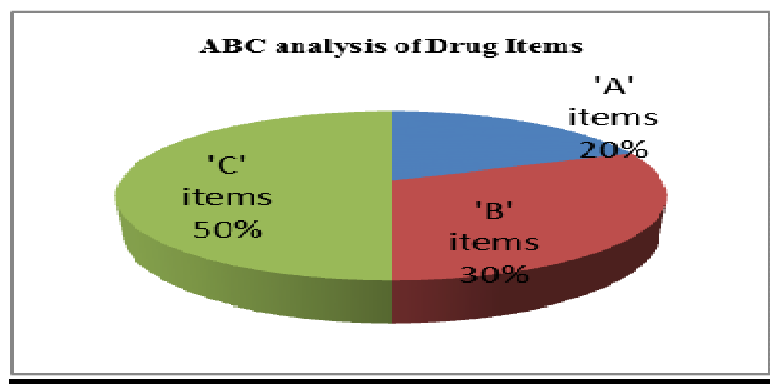

Figure $1 \mathrm{ABC}$ analysis of drugs of pharmacy department at Hospital 1

$\mathrm{ABC}$ analysis of drugs of pharmacy department at Hospital 2 is shown in "Table 2".

TABLE II

ABC ANALYSIS OF DRUGS OF PHARMACY

DEPARTMENT AT HOSPITAL 2

\begin{tabular}{|c|c|c|c|}
\hline Category & Items & $\%$ Items & $\begin{array}{c}\% \\
\text { Consumption(Value) }\end{array}$ \\
\hline 'A' items & 123 & 33.79 & 70.19 \\
\hline 'B' items & 102 & 28.03 & 19.85 \\
\hline 'C' items & 139 & 38.18 & 9.96 \\
\hline $\begin{array}{c}\text { Total no } \\
\text { of items }\end{array}$ & 364 & 100 & 100 \\
\hline
\end{tabular}

As per "Table 2" the following are the interpretations of $\mathrm{ABC}$ analysis of pharmacy drugs at Hospital 2:

- 'A' Items: 123 items accounting for $33.79 \%$ of total items \& $70.19 \%$ of total consumption in value.

- 'B' Items: 102 items accounting for $28.03 \%$ of total items \& $19.85 \%$ of total consumption.

- 'C' Items: 139 items accounting for $38.18 \%$ of total items \& $9.96 \%$ of total consumption.

$\mathrm{ABC}$ analysis of pharmacy drugs at Hospital 2 is also shown graphically through "Figure 2".

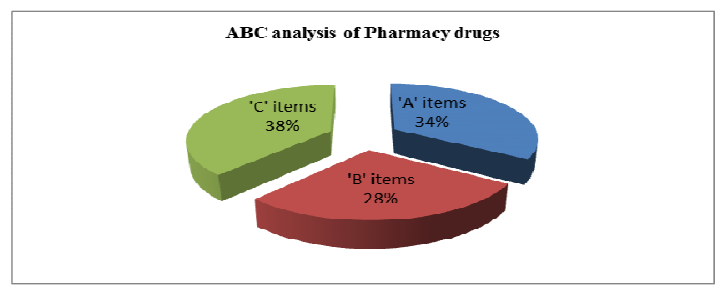

Figure $2 \mathrm{ABC}$ analysis of drugs of pharmacy department at Hospital 2 
VED analysis of drugs of pharmacy department at Hospital 1 is shown in 'Table 3'. Here the drugs have been classified on the basis of criticality of items.

TABLE III

VED ANALYSIS OF DRUGS OF PHARMACY DEPARTMENT AT HOSPITAL 1

\begin{tabular}{|c|c|c|c|}
\hline Category & Items & $\%$ Items & classification \\
\hline Vital & 27 & 9.57447 & Vital \\
\hline Essential & 165 & 58.5106 & Essential \\
\hline Desirable & 90 & 31.9149 & Desirable \\
\hline $\begin{array}{c}\text { Total no of } \\
\text { items }\end{array}$ & 282 & 100 & Total no of items \\
\hline
\end{tabular}

As per "Table 3" the following are the interpretations of VED analysis of pharmacy drugs at Hospital 1:

- 'V' Items: There are 27 items which are vital for patient care in this category.

- $\quad \mathrm{E}$ ' items: There are 165 essential items for patient care.

- $\quad$ 'D' Items: There are 90 desirable items.

VED analysis of pharmacy drugs at Hospital 1 is also shown graphically in "Figure 3".

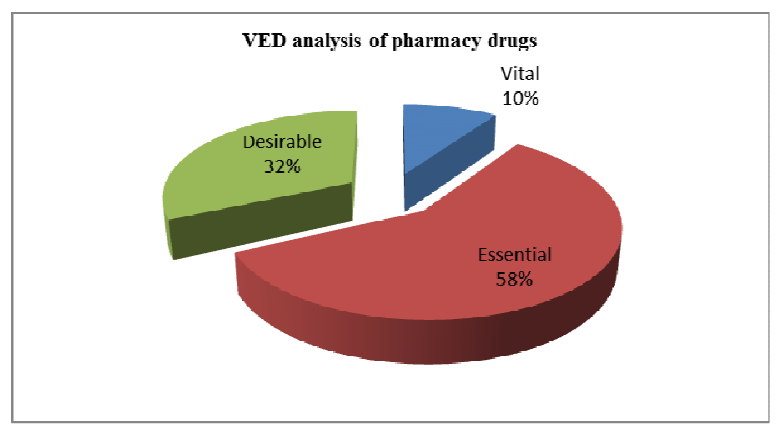

Figure 3 VED analysis of drugs of pharmacy department at Hospital 1

VED analysis of drugs of pharmacy department at Hospital 2 is shown in 'Table 4.'

TABLE IV

VED ANALYSIS OF DRUGS OF PHARMACY DEPARTMENT AT HOSPITAL 2

\begin{tabular}{|c|c|c|c|}
\hline Category & Items & $\%$ Items & classification \\
\hline Vital & 65 & 17.8 & Vital \\
\hline Essential & 236 & 64.8 & Essential \\
\hline Desirable & 63 & 17.4 & Desirable \\
\hline $\begin{array}{c}\text { Total no of } \\
\text { items }\end{array}$ & 364 & 100 & Total no of items \\
\hline
\end{tabular}

As per "Table 4" the following are the interpretations of VED analysis of pharmacy drugs at Hospital 2:

- 'V' Items: There are 65 items which are vital for patient care in this category.

- $\quad$ 'E' items: There are 236 essential items for patient care.

- $\quad$ 'D' Items: There are 63 desirable items.

VED analysis of pharmacy drugs at Hospital 2 is also shown graphically in "Figure 4".

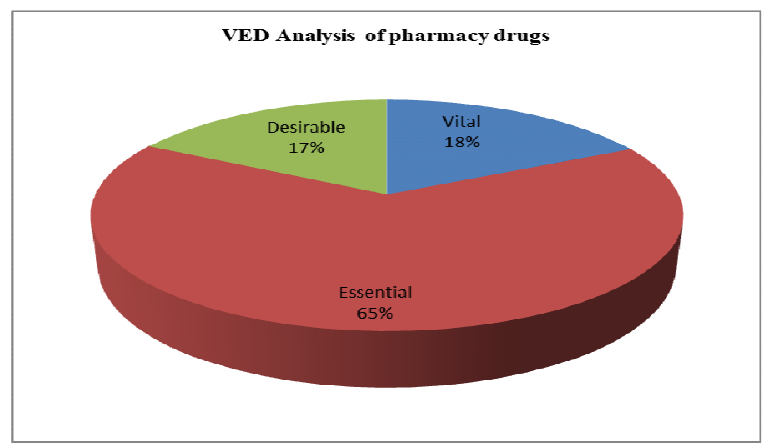

Figure 4 VED analysis of drugs of pharmacy department at Hospital 2

SDE analysis of drugs of pharmacy department at Hospital 1 is shown in 'Table 5'. Here the drugs have been classified on the basis of procurement, difficulty and market availability of items.

\section{TABLE V}

SDE ANALYSIS OF DRUGS OF PHARMACY DEPARTMENT AT HOSPITAL 1

\begin{tabular}{|l|c|l|l|}
\hline \multicolumn{1}{|c|}{ Category } & Items & $\%$ Items & \multicolumn{1}{|c|}{ classification } \\
\hline $\begin{array}{l}\text { Scarce to } \\
\text { obtain }\end{array}$ & 6 & 2.12766 & Scarce to obtain \\
\hline $\begin{array}{l}\text { Difficult to } \\
\text { obtain }\end{array}$ & 33 & 11.7021 & Difficult to obtain \\
\hline $\begin{array}{l}\text { Easy to } \\
\text { obtain }\end{array}$ & 243 & 86.1702 & Easy to obtain \\
\hline $\begin{array}{l}\text { Total no of } \\
\text { items }\end{array}$ & 282 & 100 & Total no of items \\
\hline
\end{tabular}

As per "Table 5" the following are the interpretations of SDE analysis of pharmacy drugs at Hospital 1:

- $\quad$ 'S' Items: These are scarce items especially imported items and are those which are on short supply. There are 6 items.

- $\quad$ 'D' Items: These are available with difficulty in indigenous market and cannot be procured easily. There are 33 items.

- $\quad$ 'E' Items: These refer to items which are easily available. There are 243 items. 
SDE analysis of pharmacy drugs at Hospital 1 is also shown graphically through "Figure 5".

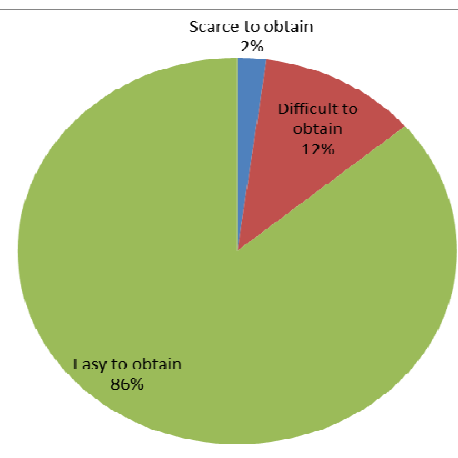

Figure 5 SDE analysis of drugs of pharmacy department at Hospital 1

SDE analysis of drugs of pharmacy department at Hospital 2 is shown in "Table 6.

TABLE VI

SDE ANALYSIS OF DRUGS OF PHARMACY

DEPARTMENT AT HOSPITAL 2

\begin{tabular}{|c|c|c|c|}
\hline Category & Items & $\%$ Items & classification \\
\hline $\begin{array}{c}\text { Scarce to } \\
\text { obtain }\end{array}$ & 10 & 2.7 & Scarce to obtain \\
\hline $\begin{array}{c}\text { Difficult } \\
\text { to obtain }\end{array}$ & 72 & 19.8 & $\begin{array}{c}\text { Difficult to } \\
\text { obtain }\end{array}$ \\
\hline $\begin{array}{c}\text { Easy to } \\
\text { obtain }\end{array}$ & 282 & 77.5 & Easy to obtain \\
\hline $\begin{array}{c}\text { Total no } \\
\text { of items }\end{array}$ & 364 & 100 & Total no of items \\
\hline \multicolumn{2}{|c|}{ As per "Table 6" the following are the }
\end{tabular}

interpretations of SDE analysis of pharmacy drugs at Hospital 2:

- $\quad$ 'S' Items: These are 10 scarce items -especially imported items- and are those which are on short supply.

- 'D' Items: These are difficult items which are available in indigenous market but cannot be procured easily. It includes 72 items.

- $\quad$ 'E' Items: These refer to items which are easily available locally \& include 282 items.

SDE analysis of pharmacy drugs at Hospital 2 is also shown graphically in "Figure 6".

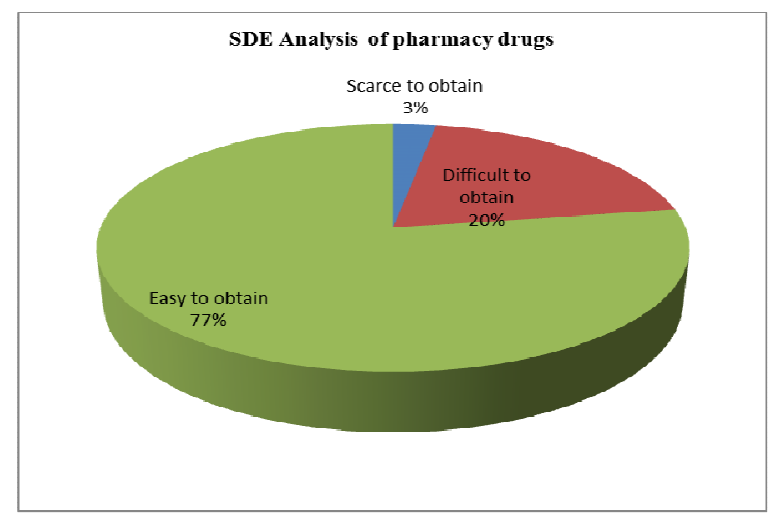

Figure 6 SDE analysis of drugs of pharmacy department at Hospital 2

MUSIC-3D analysis of drugs of pharmacy department at Hospital 1 is shown in 'Table 7'. MUSIC -3D analysis of pharmacy drugs is based on $\mathrm{ABC}$ (High or Low consumption), VED (critical or non-critical) and SDE (long lead time or short lead time) analysis.

\begin{tabular}{|c|c|c|c|c|}
\hline \multicolumn{5}{|c|}{$\begin{array}{c}\text { TABLE VII } \\
\text { MUSIC-3D ANALYSIS OF DRUGS OF } \\
\text { DEPARTMENT AT } \\
\text { HOSPITAL } 1\end{array}$} \\
\hline & \multicolumn{2}{|c|}{$\begin{array}{l}\text { High consumption } \\
\text { value items }\end{array}$} & \multicolumn{2}{|c|}{$\begin{array}{l}\text { Low consumption value } \\
\text { items }\end{array}$} \\
\hline & $\begin{array}{l}\text { Long lead } \\
\text { time }\end{array}$ & $\begin{array}{l}\text { Short lead } \\
\text { time }\end{array}$ & $\begin{array}{l}\text { Long } \\
\text { lead time }\end{array}$ & $\begin{array}{l}\text { Short lead } \\
\text { time }\end{array}$ \\
\hline \multirow{2}{*}{$\begin{array}{l}\text { Critical } \\
\text { Non- } \\
\text { critical }\end{array}$} & HLC ( - ) & $\begin{array}{l}\mathrm{HSC} \\
(0.7 \%)\end{array}$ & $\begin{array}{c}\text { LLC } \\
(7.09 \%)\end{array}$ & LSC (5.3\%) \\
\hline & $\begin{array}{c}\text { HLN } \\
(1.06 \%)\end{array}$ & $\begin{array}{c}\mathrm{HSN} \\
(18.08 \%)\end{array}$ & $\begin{array}{c}\text { LLN } \\
(4.25 \%)\end{array}$ & LSN (63.4\%) \\
\hline
\end{tabular}

Percentage distribution of pharmacy drugs under MUSIC-3D analysis for hospital 1 is shown in 'Table 8'. TABLE VIII

PERCENTAGE DISTRIBUTION OF PHARMACY DRUGS UNDER MUSIC - 3D ANALYSIS AT HOSPITAL 1

\begin{tabular}{|l|c|c|}
\hline CATEGORY & ITEMS & $\%$ \\
\hline HLC & 0 & 0 \\
\hline HSC & 2 & 0.7 \\
\hline HLN & 3 & 1.06 \\
\hline HSN & 51 & 18.08 \\
\hline LLC & 20 & 7.09 \\
\hline LSC & 15 & 5.3 \\
\hline LLN & 12 & 4.25 \\
\hline LSN & 179 & 63.4 \\
\hline Total no of items & 282 & 100 \\
\hline
\end{tabular}


MUSIC-3D analysis of drugs of pharmacy department at Hospital 1 is also shown graphically in "Figure 7".

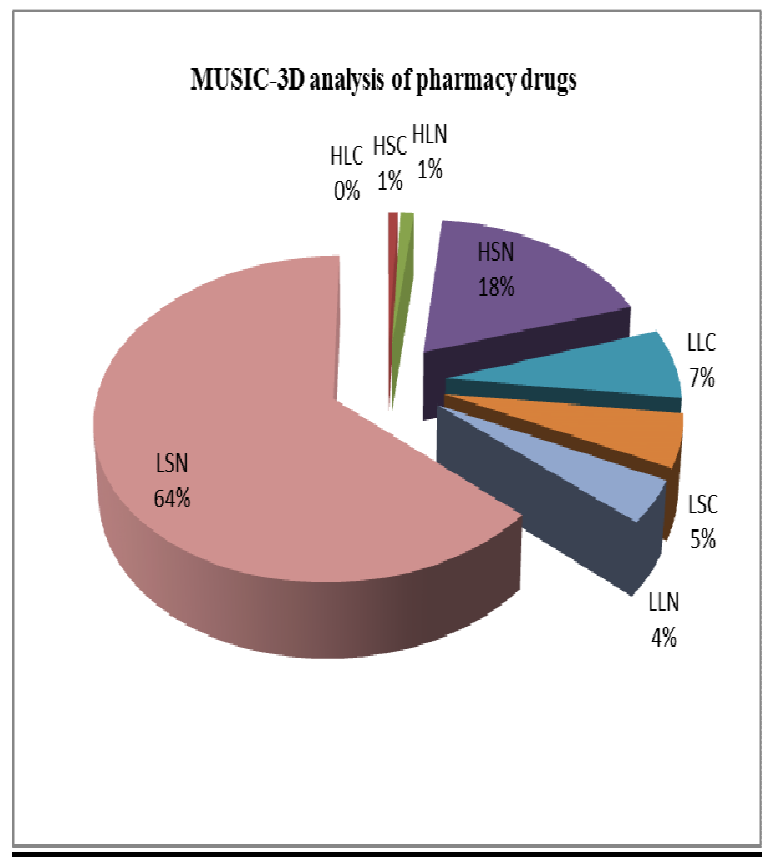

Figure 7: MUSIC-3D analysis of drugs of pharmacy department at Hospital 1

MUSIC-3D analysis of drugs of pharmacy department at Hospital 2 is shown in “Table 9'.

TABLE IX

MUSIC-3D ANALYSIS OF DRUGS OF PHARMACY DEPARTMENT AT

HOSPITAL 2

\begin{tabular}{|l|c|c|c|c|}
\hline \multirow{4}{*}{} & \multicolumn{2}{|c|}{$\begin{array}{c}\text { High consumption } \\
\text { value items }\end{array}$} & \multicolumn{2}{c|}{$\begin{array}{c}\text { Low consumption value } \\
\text { items }\end{array}$} \\
\cline { 2 - 5 } & $\begin{array}{l}\text { Long } \\
\text { lead time }\end{array}$ & $\begin{array}{c}\text { Short lead } \\
\text { time }\end{array}$ & $\begin{array}{c}\text { Long } \\
\text { lead time }\end{array}$ & $\begin{array}{c}\text { Short lead } \\
\text { time }\end{array}$ \\
\hline \multirow{4}{*}{$\begin{array}{l}\text { Critical } \\
\text { Non- } \\
\text { critical }\end{array}$} & HLC(5.7 & HSC & LLC & LSC (4.94 \\
& HLN & $(3.29 \%)$ & $(4.39 \%)$ & $\%)$ \\
\cline { 2 - 5 } & $(2.47 \%)$ & $(22.25 \%)$ & $(9.89 \%)$ & $\%)$ \\
\hline
\end{tabular}

Percentage distribution of pharmacy drugs under MUSIC - 3D analysis for hospital 2 is shown in "Table 10 .
MUSIC-3D analysis of drugs of pharmacy department at Hospital 2 is also shown graphically in "Figure 8".

TABLE $X$

PERCENTAGE DISTRIBUTION OF PHARMACY DRUGS UNDER MUSIC - 3D ANALYSIS AT HOSPITAL 2

\begin{tabular}{|l|c|c|}
\hline CATEGORY & ITEMS & $\%$ \\
\hline HLC & 21 & 5.76 \\
\hline HSC & 12 & 3.29 \\
\hline HLN & 9 & 2.47 \\
\hline HSN & 81 & 22.25 \\
\hline LSC & 16 & 4.39 \\
\hline LLN & 18 & 4.94 \\
\hline LSN & 36 & 9.89 \\
\hline Total no of items & 171 & 46.97 \\
\hline
\end{tabular}

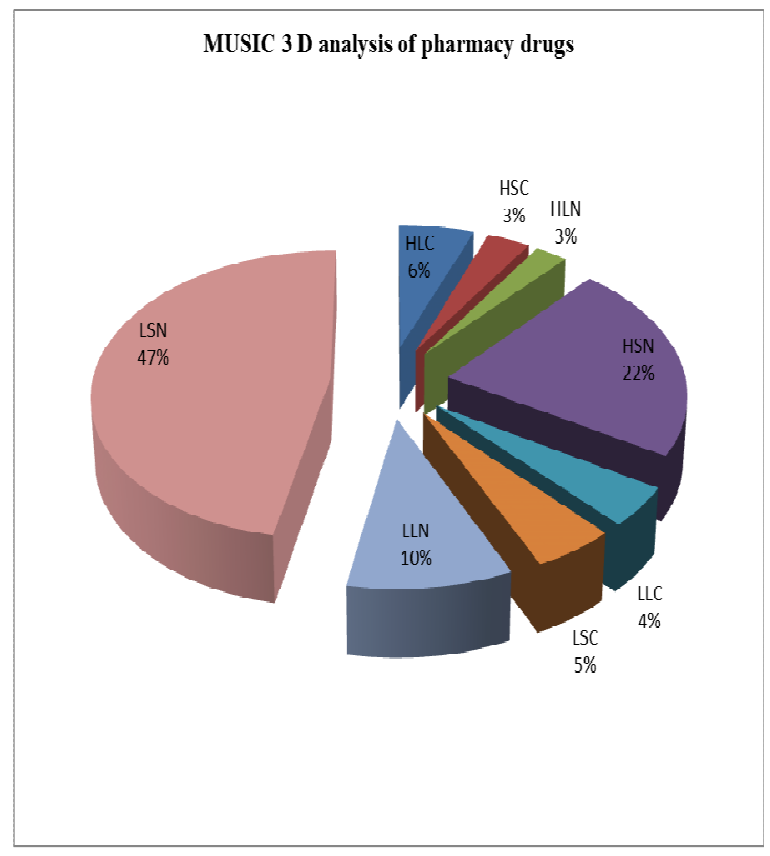

Figure 8 MUSIC-3D analysis of drugs of pharmacy department at Hospital 2 


\section{CONCLUSION}

The conventional $\mathrm{ABC}$ analysis is not an effective selective control mechanism, as there are other influencing mechanisms, like criticality and availability, which influence a great deal on controlling the materials. Thus, the three-dimensional approach MUSIC -3D is helpful to classify all materials into eight categories and to control the materials effectively on all aspects and achieve cost reduction, in order to facilitate the materials department as a profit center. The initial efforts required to implement MUSIC-3D may be quite high but once implemented only a marginal effort is needed to maintain and improve it. The benefits are immense. The importance of inventory control is now recognized by the hospital administrators. Its basic objectives are to reduce investment in inventories and simultaneously avoid stock-out situation. An effective inventory control balances the two objectives to optimum advantage. Computerization, automation and use of technique like MUSIC-3D will aid in achieving these objectives.

It is imperative that all measures for the prevention of stock out situations should be implemented. Availability of pharmaceutical products is essential for patient satisfaction. It is also an essential requisite for provision of life saving, effective and efficient healthcare. Frequency of stock outs is an indicator to assess the effectiveness of the stores department and the materials management. The MUSIC $-3 \mathrm{D}$ technique needs to be adopted as a routine practice for optimal use of resources and elimination of out-ofstock situations in the hospital pharmacy. MUSIC 3-D aids in efficient management of the pharmacy stores, as it contributes to not only improvement in patient care but also judicious use of resources as well.

\section{REFERENCES}

[1] Gopalakrishnan, P, (ed). "Purchasing and Materials Management", New Delhi : Prentice Hall Of India Pvt Ltd.,pp 79, 2000.

[2] Gupta, S. and Sunil, K. (ed)., "Hospital Stores Management”, .New Delhi : Jaypee Publications, 2000.

[3] Benito E. Flores, D. Clay Whybark, "Multiple Criteria ABC Analysis", International Journal of Operations \& Production Management, Vol. 6 Issue: 3, pp.38 - 46 , 1986.

[4] Viswanathan, S., Bhatnagar, Rohit' "The application of $\mathrm{ABC}$ analysis in production and logistics: an explanation for the apparent contradiction", International Journal of Services and Operations Management, Vol. 1, Number 3, pp. 257-267, 2005.

[5] Alberto Gabbay Canen, Roberto D. Galvão "An Application of $A B C$ Analysis to Control Imported Material", Interfaces, Volume 10, Issue 4, 1980.

[6] M Devnani, AK Gupta, and R Nigah,, "ABC and VED Analysis of the Pharmacy Store of a Tertiary Care Teaching, Research and Referral Healthcare Institute of India”, Journal of Young Pharmacists, April-June; 2(2): 201-205.,2010 .

[7] Anand T, Ingle GK, Kishore J, Kumar R, “ $A B C$ - VED Analysis of a Drug Store in the Department of Community Medicine of a Medical College in Delhi", Indian Journal of Pharmaceutical Science. Jan;75(1):113-7., 2013.

[8] Mahatme M, Dakhale G, Hiware S, Shinde A, Salve A., "Medical store management: an integrated economic analysis of a tertiary care hospital in central India', Journal of Young Pharmacists, April;4(2):114-8, 2012.

[9] Kant S, Pandaw CS, Nath LM, "A management technique for effective management of medical store in hospitals. Medical store management technique.", Journal of Academy of Hospital Administration, 8-9(2-1):41-7, 1997. 